\title{
An Empirical Study on Lexical Errors in English Writing of Chinese College Students and Countermeasures
}

\author{
Nuo Chen \\ Southwest University of Political Science and Law, China.
}

\begin{abstract}
How to cite this paper: Nuo Chen (2021). An Empirical Study on Lexical Errors in English Writing of Chinese College Students and Countermeasures. The Educational Review, USA, 5(7), 196-203. DOI: $10.26855 /$ er.2021.07.002
\end{abstract}

Received: June 20, 2021

Accepted: July 15, 2021

Published: July 20, 2021

Corresponding author: Nuo Chen, Southwest University of Political Science and Law, China.

Email: chennuocici@163.com

\begin{abstract}
Based on an empirical study on lexical errors in the English writing of 90 Chinese college students whose composition score ranges from 30 to 45 out of the full mark of 50, four types of 640 lexical errors are detected in this study which involve 60 (9.37\%) collocation errors, 210 (32.81\%) incorrect parts of speech, 150 (23.43\%) wrong spellings and 220 (34.38\%) unacceptable word choices. On the basis of those errors, this paper found that the causes include carelessness, poor memory of word spelling, memorizing words isolated from context and incorrect use of so-called high-level vocabularies. Accordingly, four countermeasures targeted at the lexical error are proposed including promoting writing through reading, lexical chunks teaching, emphasizing recitation, application of multimodal metaphor theory and Network technology, which can shed light on EFL teaching and learning.
\end{abstract}

Keywords

Lexical Errors, English Writing, Chinese College Students, Countermeasures

\section{Introduction}

The writing of students in a language indicates their proficiency in the language (Hong, 2007). Writing, as an output of language acquisition, is a complex and creative activity of thinking, which can comprehensively reflect students' creative, logic and critical thinking, the ability of making sentences and organizing the whole passage. Lu (2016) regards writing as one of the most effective ways to improve critical thinking and communication. So, she advocates that College English writing should be a mandatary course. EFL writing is not only always one of the most difficult points in teaching and learning, but also a tough and long process to be improved which required much effective input that does not mean only reciting some separative words or fixed sentence structures. In China, the average core of CET 4 and CET 6 of National College Students is only 7 out of 15, which indicates that Chinese college students have a poor command of English writing which mainly lies in vacuous content, narrow mind, incorrect grammar and use of words, simple sentence structure, Chinese pattern, poor vocabulary, etc. Among these, lexical errors seem more significant than others. $\mathrm{Li}$ (2003) and Wen (2005) find Chinese college students' lexical errors in their English Writing account for 70\% among the total errors. In his article the Significance of Learners' Errors, Corder (1967) points out learners' errors are what the language system learners use in the process of the language acquisition at some stage. In last decades, error analysis gained much attention and development in L2 writing study, but it is a pity that Chinese students' English writing ability still has no progress for lacking effective ways. Therefore, based on an empirical study on 90 Chinese college students' English writing, this thesis aims at finding out their errors, determining the causes and putting forward 
some countermeasures targeted at those errors.

\section{Literature Review}

As one of the most influential theories in SLA research, error analysis involves analysing the errors made by second language learners by comparing with the standard language (James, 1988). Crystal (1999) believes that error analysis is the study of unacceptable forms of language in language teaching, especially in the process of learning a foreign language. According to James (2001), error analysis is the study of language ignorance, which is to examine what people do not know and how they try to solve it. Brown (2000) gives another definition of error analysis as the observation, analysis and classification of errors.

Errors detected in EFL writing are analyzed and categorized into different classifications. Dulay, Burt, and Krashen (1982) categorize the errors in EFL writing into six different categories: wrong use grammatical affix, misunderstanding of word meaning, unacceptable rules, incorrect part of speech, wrong functional words, and misordering. James (1998) puts forward five classifications of errors which include grammatical errors (adjectives, adverbs, articles, nouns, possessions, pronouns, prepositions and verbs), substance errors (capitalization, punctuation and spelling), lexical errors (word formation and word selection), syntactic errors (coordination, subordination, sentence structure and ordering), and semantic errors (ambiguous communication and miscommunication). Gui and Yang (2003) classify errors in Chinese Learners' English Corpus into 11 categories: morphology, verb phrase, noun phrase, pronoun, adjective phrase, adverb, preposition phrase, conjunction, vocabulary, collocation and syntax. Among them, morphology errors include spelling, word formation and incorrect capitalization, while vocabulary errors include word order, part of speech, substitution and ellipsis, redundancy, repetition and semantic ambiguity.

Error analysis is widely used in SLA study, but in writing analysis, there are usually different results about errors due to different classification and subjects. Some studies conducted in Ghanaian universities indicated that grammatical and lexical errors do exist in students' writing (Dako, 1997; Gogovi, 1997; Awuah-Boateng, 1998; Edu-Boandoh, 1997; Mahama, 2012; Mireku-Gyimah, 2008). These studies noted the following as grammatical and lexical errors university students make in their L2 writings: concord errors, wrong register, wrong tense, wrong word use, wrong collocation, ambiguity, punctuation errors, and wrong idiomatic expression use. Owu-Ewie and Williams (2017) study grammatical and lexical errors in students' English composition writing and come a conclusion that grammatical errors account for $61.4 \%$ including agreement, article, tense, preposition and number, while, lexical errors account for $38.6 \%$ including homophone induced and semantic. Based on an empirical analysis of 290 compositions from Chinese Learners' English corpus (CLEC), He (2009) found that the most frequent lexical errors were spelling errors, followed by substitution errors. Collecting English compositions in the final examination of non-English majors in Zhongshan University, Huang (2004) finds the most common lexical errors are incorrect spellings which account for $87 \%$.

According to previous study, firstly, some scholars' researches considered too many aspects so that they can hardly focused on a specific aspect which might lead to unreliable judgement of errors because some types of errors can be classified into different categories. Secondly, the materials used in some studies crossed different grades of learners who might commit different errors at different levels so that the data were not representative for students at a particular EFL writing level. Thirdly, some previous studies just focused on error analysis and did not analyze causes behind the errors or propose well-directed teaching measures. Therefore, based on an empirical study on Chinese college students with a similar English writing level, this thesis focuses on the lexical errors, analyzes causes of those lexical errors and puts forward some countermeasures targeted at the errors.

\section{Methodology}

\subsection{Research question}

(1) What are the lexical errors in L2 (English) writing of Chinese college students?

(2) What is the proportion of different types of lexical errors in L2 (English) writing of Chinese college students?

(3) What are the causes of those lexical errors?

(4) What are the countermeasures targeted at the lexical errors?

\subsection{Subjects}

The subjects are 90 non-English majors in a university in China whose writing score ranges from 30 to 45 points with 50 as the full mark in a formal writing competition. The subjects are required to write a composition on "Should Family Cars Encouraged in China?” in one hour. 


\subsection{Data collection}

The 90 writing compositions come from a formal writing competition. And the final score of their compositions is the average score of three English teachers. Then, the author selects out the compositions with score ranging from 30 to 45.

\subsection{Data analysis and processing}

The errors of the compositions are detected and judged by the author with the help of the automatic correcting system (www.pigai.org), Corpus of Contemporary American English (COCA) and online dictionaries including Collins, Oxford and Webster to check the lexical errors. At the same time, the lexical errors are recorded with Microsoft Excel for selecting lexical errors in different categories. Finally, the errors are checked by another two English teachers.

\section{Results and discussion}

The analysis of the data and discussion of the findings are thematically done based on the research questions posed earlier in the study. The analysis is done by categorizing the lexical errors into collocation of words, part of speech, spelling and choice of words. The following are the discussions and responses to the research questions asked earlier:

Research question 1: What are the lexical errors in L2 (English) writing of Chinese college students?

This question is proposed to find out the specific types of lexical errors which are confused sometimes because some errors seemly can be classified into different categories. But after prudent analysis and discussion, the lexical errors are classified into four main categories including collocation of words, part of speech, spelling and choice of words.

\subsection{Collocation of words}

The realm of collocation has to do with meaning relation between lexical items (Fatima, 2015). In all human languages, there is a kind of 'natural order' in which words are arranged or related to one another in sentences so that when a word occurs in a given context, the related or naturally co-occurring words will automatically come to the mind. It becomes an error, therefore, if students inappropriately pair or arrange such 'naturally' co-occurring lexical items in a text. Collocations are word partners that sound natural to native speakers. For example, "raise awareness" is a collocation, but "elevate awareness" is not. In this study, the author used Corpus of Contemporary American English (COCA) and online dictionaries to check the unacceptable collocation words. The following are some examples about incorrect collocation of words:

1) Family cars provide a sanctuary away from distracting public transportation chatters such as noisy cars and crowed buses.

According to Collins, the word "distract" usually collocates with "somebody" or "attention" in the structure of "distract sb./one's attention from sth.”

2) Our government never stop us to produce or buy family car, instead, they plunge countless money in search for clean energy cars.

After checking the word "plunge" in online dictionaries, the definition apparently cannot collocate with the word "money". And according to the context, the word "plunge" may be corrected as "invest" with $8^{\text {th }}$ frequency of 3059 on COCA.

3) I hope we can take new energy cars in an early future.

After checking the frequency of "take cars" on COCA, it is found that the frequency is only 24. Searching the collocation of verb plus cars on COCA, “drive” bears the highest frequency with 1092 times.

4) Our government also erected many rules to solve the traffic congestion.

After checking the frequency of "erect rules" on COCA, no such collocation is found. Then after searching the collocation of verb plus rules on COCA, the frequency shows in Table 1. Therefore, we can choose "make" "apply" and "set" to express the similar meaning according to the context.

Table 1. Collocation of Verbs plus “Rules” on COCA

\begin{tabular}{ccc}
\hline No. & Verb+rules & Frequency \\
\hline 1 & Follow & 2,271 \\
2 & Make & 2,805 \\
3 & Know & 1,723 \\
4 & Apply & 1,325 \\
5 & Play & 1,319 \\
6 & Change & 1,256 \\
7 & Set & 1,220 \\
\hline
\end{tabular}




\subsection{Part of speech}

The errors of part of speech refer to the confusion of word formation which involves noun, verb, adjective, adverb, conjunction, pronoun, preposition or interjection. Among them the incorrect use often occurs between noun, adjective, adverb and verb. The following are examples of errors of parts of speech:

1) It did bring much convenience and merry to the car and families.

2) As the number of families soaring increased, many social issues came along with that.

3) We can't deprive this honor from many endeavor people.

4) It is convenience for them to control us.

5) Along with the fast development of high-technology, most of us enjoy the convenient and fast of the 21st century

6) Global warming becomes a trend that can't be easily reversed in recently years.

7) The car industry develops quickly, which improves the ability of producting to decline the price of the car.

8) Industrial pollution already contributed to climate's change.

9) Family cars can minor the quantity of individual's cars and then depressure the transportation.

10) We should build the conscious to protect environment.

11) The exist of family cars needs us ponder.

12) A number of family cars detrimated the environment and cause the deterioration of environment quality.

13) People like to show off their cars, which is a bad model for children to cultivate the modest.

14) Whenever I seat in the dad's car back to home town, there is a feel of new year.

\subsection{Spelling}

The errors of spelling often take place because of carelessness of writers but indeed no one can avoid wrong spellings which surprisingly account for $23.43 \%$ among the types of lexical errors. The disorder of some confused letters and homophone induced errors often lead to wrong spelling of words. The following are examples of incorrect spellings:

1) Bus and rail way transportations are supposed to be better choices for us.

2) They want to take energous kids to go on vacation.

3) Individual obession with family cars has triggered the tragic consequence of greenhouse effect.

4) By no means can theory be seperated from specific condition, this is the first thing I want to underlie.

5) They cost energy and fossil fuel extravergantly.

6) They ablamed China pollute the globe.

7) Although family cars cannot prevent people buy luxyous cars, but it do depress the quantity of cars.

\subsection{Choice of words}

Word choice errors are often due to interference from the writer's first language and are sometimes called false-cognate translation errors. The errors seem developmental in nature, coming from a lack of knowledge of the different vocabulary choices available in English or collocations required by a particular context. The following are examples of unacceptable word choices:

1) Economic growth promotes family cost to become a super-heated dispute.

2) Pollution is aquestion that should be attached more significance by our government.

3) They just want to stop our industrial stamps and stay in age of agriculture

4) Family cars are necessary for many people, not only working but also using.

5) The fast development of car industry declines the price of the car.

6) Having no ascendance in environment, encouraging to use family cars does harm to transport security.

7) People decrease to use their own cars may save the time they spend

8) As we know, the transportation is a massive problem in huge cities, like Beijing and Shanghai where the car can be stocked on the way over an hour in rush hours.

9) Family cars can minor the quantity of individual cars and then depressure the transportation.

10) Family cars can depress the quantity of individual cars.

Research question 2: What is the proportion of different types of lexical errors in L2 (English) writing of Chinese college students?

The lexical errors are classified into four categories including collocation of words, part of speech, spelling and choice of words. In all there were 640 lexical errors made up 60 (9.37\%) wrong collocations of words, 210 (32.81\%) incorrect parts of speech, 150 (23.43\%) wrong spellings and 220 (34.38\%) unacceptable word choices. The following is 
a representation of the frequency table and bar chart of the lexical errors (see Table $2 \&$ Figure 1):

Table 2. Frequency of Lexical Errors

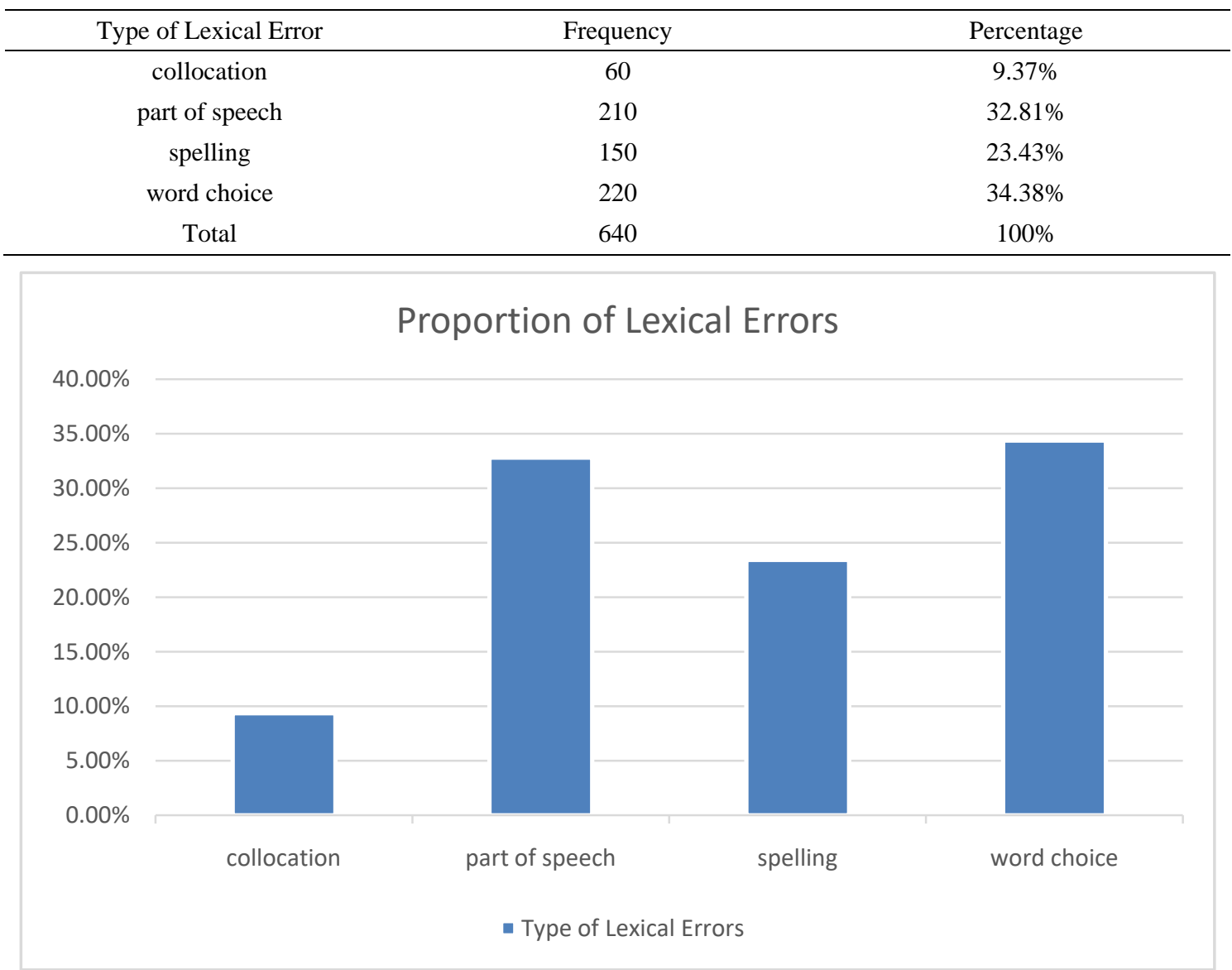

Figure 1. Proportion of lexical Errors.

Question 3: What are the causes of those errors?

As we can see from the previous analysis, the paper finds that firstly, carelessness and poor memory of word spelling lead to much wrong spellings. Secondly, most students memorize words isolated from context and don't know the correct use of vocabulary so that they commit collocation errors and unacceptable word choices. What is the most prominent important cause is that many students tend to use those so-called high-level vocabularies, but most of students use them in an incorrect and unacceptable way, which leads to errors of spelling, collocation, and word choice and part of speech.

\section{Countermeasures for the Errors}

This chapter answers the fourth question that what are the countermeasures targeted at the lexical errors. In order to tackle the problems of collocation error, incorrect part of speech, wrong spelling and unacceptable choice of words. Four teaching measures are proposed including promoting writing through reading, lexical chunks teaching, emphasizing recitation, application of multimodal metaphor theory and Network technology.

\subsection{Promoting Writing through Reading}

In most college comprehensive English textbooks in China, each unit is arranged according to the topic based on the passage content, and the after-reading task of writing is also related to the unit topic, which creates convenience for the integration of reading and writing. Writing course is by no means dispensable, but should be an important part of College Comprehensive English course, which should be closely combined with intensive reading course so that reading as an input activity and writing as an output activity can complement each other. The teacher in English reading class, 
usually explains the vocabularies and various sentence patterns in the text to help students understand the word meaning and make sentences. When explaining the vocabularies and phrases in the passage, the teacher should try to stick to the theme so that students can deeply understand the new words in context and use them flexibly, which is conducive to writing.

In addition to the text materials, the teacher can supplement some reading materials related to the unit theme for students to read after class and the teacher can organize some activities to lead students to discuss in class. No matter teachers or students must bear in mind that reading is the premise of writing. Only with a certain amount of reading accumulation, effective output like writing can take place naturally because reading can provide context and cognitive hold for vocabulary acquisition, expand students' thinking, broaden their horizons. Through reading, students can accumulate vocabulary related to the theme, and learn how to express themselves with those words, which can effectively avoid unacceptable word choice.

\subsection{Lexical Chunks Teaching}

Chunk theory was first proposed by American psychologist George A. Miller. Chunk is a kind of prefabricated language, which is a semi-fixed and patterned structure, such as phrases, collocations, idioms, etc. Memorized and stored in the form of chunks, language can become fluent with a little processing, which can greatly improve the efficiency of production. In addition, chunk teaching can help students get rid of memorizing words isolated from context, thus avoiding wrong collocation and improve the accuracy of language.

In order to ensure the fluency, accuracy and authenticity of the language, students need to aware that Chinese and English are not one-to-one correspondence and memorizing words in isolation according to the vocabulary list is not only easy to forget, but also easy to make mistakes. Teachers should, in EFL teaching, increase the input of lexical chunks through reading and listening to cultivate students' awareness of lexical chunks, teach students how to recognize lexical chunks and accumulate lexical chunks to realize the whole storage and retrieval of lexical chunks and to improve the efficiency and accuracy of writing.

\subsection{Emphasizing Recitation}

Chinese education has the tradition of emphasizing recitation no matter in L1 or L2 teaching. Diligent recitation can make us accumulate more knowledge. As an effective way to learn English, reciting can internalize language knowledge, enhance learners' sensitivity to language, cultivate language sense and develop English thinking, and create repetitive stimulation which is helpful to the establishment and enhancement of conditioned reflex so as to reduce wrong spellings to some extent. Dai et al. (2010) find students have made greater progress in English and English writing by reciting texts. By reciting the text, low-level students learn more formulaic phrases, while the high-level students learn to use them more accurately. However, English teachers should be aware of reciting a whole paragraph or text will increase students' burden. So, teachers can select some good words and paragraphs together with students in intensive or extracurricular reading material, encouraging students to read and recite them, and to use them flexibly in writing with innovation. What's also important is that teachers should frequently praise those students who use what they recite in flexible, creative and well-reasoned ways, which can encourage students to use what they have learned with consciousness and cultivate their creativity.

\subsection{Application of Multimodal Metaphor Theory}

Multimodal metaphor is a relative conception with mono-modal metaphor. Mono-modal metaphor is a kind of metaphor where the source domain and the target domain are explained by only one mode, such as language metaphor and image metaphor. Multimodal metaphor means the source domain and the target domain use different modes to express metaphor. Foreville (2009), the leader of multimodal metaphor theory, defined multimodal metaphor, in a broad sense, as a metaphor constructed by two or more modes. He also defined modality as "a symbol system that can be interpreted by using specific perceptual process" which is closely related to the five senses of human beings, and corresponding five perception modes. For the convenience of research, Foreville (1996) divides the modes into nine categories: image mode, contact mode, music mode, sound mode, written language mode, oral language mode, smell mode, taste mode and gesture mode.

The traditional teaching methods of English writing, including writing after reading, recitation and writing practice, to some extent, are effective for the improvement of students' language ability. But these measures pay too much attention to the written mode of the text and neglect the natural discourse. Therefore, in addition to the reading materials in textbooks, teachers should add some news, videos and music related to topics, and then on the basis of those multimodal inputs, assign writing tasks which are not only be limited to argumentative essays and narratives, but also poems and 
short plays. Teachers can require students perform according to their own scripts of short plays, which can help students understand the meaning of English vocabularies in a more vivid way in the natural context so as to effectively avoid incorrect word choices and collocations.

\subsection{Application of Network Technology}

The latest College English Teaching Guidance points out that teachers should make full use of Network resources to promote students' autonomous learning ability so as to realize the change from "passive learning" to "active learning".

At present, many schools use intelligent evaluation system in writing teaching. The application of Network for intelligent correction can achieve instant feedback, peer evaluation, resource sharing and so on. For example, though there are still many deficiencies in the overall evaluation of content, text and structure, the automatic correcting system (www.pigai.org) can give students timely feedback and guidance in terms of vocabulary and grammar. The system can also provide the synonyms and antonyms of some words used in students' writing, and point out spelling and collocation errors and low frequency warning, which can not only help students find out the mistakes in their choice of words and sentences, but also expand their vocabulary. Based on empirical study, Huang et al. (2015) come to the conclusion that the accuracy and fluency of students' compositions are improved after using the automatic correcting system.

With huge data, Corpus of Contemporary American English (COCA) is another useful tool for English writing which can show the frequency of words and phrase, and provide authentic collocation, frequency of words and phrases, synonyms and antonyms in specific context, which can improve students' writing ability and make their composition more authentic instead of wrongly using so-called high-level words.

\section{Conclusions}

With empirical study on 90 Chinese college students with a similar English writing level, this thesis focuses on lexical errors, conducting error analysis on their writing compositions under the guidance of the following three questions:

(1) What are the lexical errors in L2 (English) writing of Chinese college students?

(2) What is the proportion of different types of lexical errors in L2 (English) writing of Chinese college students?

(3) What are the causes of those lexical errors?

(4) What are the countermeasures targeted at the lexical errors?

As for the first and second question, four types of 640 lexical errors are detected in the study which involves 60 (9.37\%) collocation errors, 210 (32.81\%) incorrect parts of speech, 150 (23.43\%) wrong spellings and 220 (34.38\%) unacceptable word choices. As for the third question, this paper finds that carelessness and poor memory of word spelling lead to wrong spellings; memorizing words isolated from context causes collocation errors and unacceptable word choice. What is the most prominent important cause is that too many incorrect uses of so-called high-level vocabularies leads to errors of spelling, collocation, and word choice and part of speech. As for the fourth question, this thesis proposed four teaching measures including promoting writing through reading, lexical chunks teaching, emphasizing recitation, application of multimodal metaphor theory and Network technology to deal with the four types of errors, which contribute to EFL teaching and learning.

\section{References}

Awuah-Boateng, P. A. K. (1998). An analysis of students' errors based on a diagnostic test for first year students at the beginning of the 1996/97 academic year. University of Cape Coast.

Brown, H. (2000). Principles of language learning and teaching. New Jersy: Prentice.

Charles, O. and Williams, R. (2017). Grammatical and lexical errors in students' English composition writing: The case of three senior high schools (SHS) in the central region of Ghana. Sino-US English Teaching, 14(8), 463-482.

Corder, S. P. (1967). The significance of learners’ errors. International Review of Applied Linguistics, 4(5), 161-169.

Crystal, D. (1999). The penguin dictionary of language. New York: Penguin Press.

Dai, Z. Q. and D, Y. R. (2010). The role of reciting texts in Chinese students’ English learning. Foreign Language Research, (2), 46-52.

Dako, K. (1997). Features of stylistic versatility in English as observed in the writing of English graduates. In M. E. Kropp Dakubu (Ed.), English in Ghana (pp. 263-274). Accra: Black Mask.

Dulay, H. C., Burt, M. K., and Krashen, S. D. (1982). Language two. New York: Oxford University Press.

Edu-Buandoh, D. (1997). A preliminary report on the study of error patterns in the written essays of senior secondary students. In M. E. Kropp-Dakubu (Ed.), English in Ghana (pp. 95-210). Accra: Black Mask. 
Fatima, M. S. (2015). Collocation errors in English as second language (ESL) essay writing. World Academy of Science, Engineering and Technology International Journal of Cognitive and Language Sciences, 9(9).

Forceville, C. (1996). Pictorial metaphor in advertising. London \& NewYork: Routeledge.

Forceville, C. (2009). Multimodal metaphor. Berlin \& New York: Mouton de Gruyter.

Gogovi, G. A. K. (1997). Intensifier + Verb collocation in English: A case study of post diploma usage in the University of Education, Winneba. In M. E. Kropp Dakubu (Ed.), English in Ghana (pp. 46-52). Accra, GESA: Black Mask.

Gui, S. C. and Y, H. Z. (2003). Chinese learner English corpus. Shanghai: Shanghai Foreign Language Education Press.

He, H. Q. (2009). Lexical error analysis in non-English majors’ writing: A corpus based study. Foreign Languages, (3), 2-9.

Hong, L. (2007). The role of revision and teacher feedback in a Chinese college context. ASIAN AFL Journal, 9(4).

Huang, S. Y. and Zhang, Li. (2015). The influence of automatic composition review system on the writing ability of different learners. Foreign Language and Translation, (4), 70-76.

Huang, Y. C. (2004). Analysis of lexical errors in College English writing. Journal of Sun Yat sen University, (4), 305-309.

James, C. (1998). Errors in language learning and use: Exploring error analysis. New York: Routledge.

James, C. (2001). Errors in language learning and use: Exploring error analysis. Shanghai: Foreign Language Teaching Press.

Li, H. (2003). An analysis of the linguistic errors in non-English Majors writing. Dalian Maritime University.

Lu, Y. W. (2016). Research on the relationship between College English writing and College English and general education. Contemporary Foreign Language Study, (3), 31-33.

Mahama, E. S. (2012). Ghanaian English and its implications for academic writing: A case study of English on the Navrongo campus of university for development studies, Ghana. Research on Humanities and Social Sciences, 2(11), 56-63.

Mireku-Gyimah, P. B. (2008). Do students of mining and allied engineering programmes have any problems in English? Ghana Mining Journal, 10, 48-62.

Wen, H. (2005). Comparative study on errors in English composition by freshmen, sophomores and juniors major in English in SWNU. Southwest Normal University. 